\title{
Entre el discurso historiográfico y la escritura íntima: otra Javiera Carrera que emerge, vive y siente
}

\author{
"Between the historiographic discourse and the \\ personal writing: another Javiera Carrera emergers, \\ lives, and feels"
}

\author{
Carmen Gloria Soto Gutiérrez \\ Estudiante de Magíster Universidad de Chile \\ carmengloriasotog@gmail.com
}

\begin{abstract}
SÍNTESIS
La historiografía liberal del siglo XIX construyó un imaginario en torno a Javiera Carrera, limitado a un rol pasivo, propio de la mujer del periodo, dejando de lado otro tipo de accionar. A partir de esta primicia, y desde un enfoque de historia de las mentalidades, este estudio tiene por objetivo la reconstrucción del repertorio simbólico operante sobre el cuerpo de Javiera, como mujer inmersa en el contexto independista a través de sus cartas, para dilucidar cómo se posiciona o autorepresenta frente a los hechos del periodo, principalmente desde una perspectiva del cuerpo y las emociones, en cuanto mujer que vive y siente.
\end{abstract}

\begin{abstract}
The liberal historiography of the XIX built an imaginary around Javiera Carre$\mathrm{ra}$, which was limited to a pasive role, something very typical of the woman of this period and that lets out others behaviors. From this premise, and focused on History of Mentalities, this study has the aim to reconstruct the symbolic repertoire about the body of Javiera, as a woman absorbed in a national independence context. Through her letters it is possible to elucidate how she was placed or presented in front of the period's facts, mainly from the perspective of the body and emotions, as a woman who lives and feels.
\end{abstract}

Palabras claves: imaginario, cartas, historia del cuerpo y las emociones, intimidad.

Keywords: Imaginary, letters, body and emotions' history, privet life. 


\title{
Introducción
}

\begin{abstract}
“Pocos nombres femeninos de la historia americana están envueltos en una atmósfera de gloria y desgracia semejante al de Javiera Carrera. (...) Era uno de los brazos de la conspiración libertadora, en sus salones, en donde también tiempo después se estrenó la bandera de la patria vieja, realizado el proyecto por ella. (...)

Alma ardiente y apasionada, amaba la acción y desafiaba el peligro, en el círculo

de la familia dominaban completamente sus opiniones, ella gestora de la causa patriota, que empujó a sus hermanos, incluso la muerte de ellos es el resultado de
\end{abstract}

su acción"1.

La cita anterior sintetiza la principal interpretación historiográfica sobre Javiera Carrera, y base del imaginario en torno a ella (Durand, 2004)2. Ser la hija de, la esposa de, la hermana de, la que bordó la primera bandera, la que apoyó a sus hermanos, la revolucionaria, la facinerosa, la que bailaba la resbalosa, son las principales imágenes que caracterizan el accionar de esta mujer en el periodo de la Independencia. Asimismo, éstas reflejan la dicotomía entre un rol pasivo, propio de la condición de ser mujer en el periodo, y un rol activo en relación a su pertenencia a la elite y a la esfera política ${ }^{3}$.

Frente a estas interpretaciones, surge el cuestionamiento sobre cómo Javiera se desenvolvió o enfrentó los sucesos de su contexto, más allá de la reproducción de las imágenes construidas por la historiografía decimonónica. En esta lógica, relevante información nos proporcionan sus cartas, fuente documental de base y constantemente utilizada al momento de trabajar su imagen, al ser $s u$ testimonio sobre los hechos que vivió. Por ello que una primera entrada al discurso construido en torno a ella, sea a través de estos escritos.

A medida que nos adentramos en su escritura, las imágenes de una mujer totalmente pasiva o activamente reaccionaria, se desvanecen para dar paso a una Javiera que emerge entre estos dos extremos, en un tránsito entre ambos posicionamientos. Así es como sobresale, por una parte, un cuerpo que debe comportarse según las normas sociales del periodo, según lo que se espera y desea que haga, enfrentando además las vicisitudes propias del contexto y, por otra, uno que adopta una postura crítica o "silenciada". Independiente de estas dos posturas, emerge un cuerpo que a través de su 
escritura representa los cambios políticos y sociales en el territorio, y de qué forma es trastocada por estos. Asimismo, se destaca un cuerpo que habla desde la intimidad, haciendo referencia a un estado de tristeza y soledad en el que está inmersa, tanto por la lejanía de su esposo y familia, por la muerte de sus hermanos y su vivencia en el exilio. Es decir, a partir de esta escritura íntima, se nos hace visible un cuerpo que vive, pero que también siente y sufre.

Según lo planteado y teniendo por base las cartas, el objetivo de este estudio consiste en la reconstrucción del repertorio simbólico operante sobre el cuerpo de Javiera Carrera, en cuanto mujer inmersa en el contexto independista, para dilucidar cómo se posiciona o autorepresenta frente a los sucesos desde una perspectiva del cuerpo y las emociones.

Este posicionamiento se manifiesta según una lógica de presencia y ausencia. Esto se visualiza en su escritura, tanto por los desplazamientos territoriales, ya sea la lejanía de su esposo en una primera instancia y luego el exilio de Javiera en Mendoza, así como también en un nivel simbólico, quedando de manifiesto principalmente en las cartas dirigidas a su esposo. A través de esta materialidad, se expresa la ausencia del ser amado (a), ya sea por la falta de respuestas a las cartas enviadas entre los esposos, o por la expresión de melancolía y desazón a causa de la distancia entre ambos (Barthes, 45). Por otra parte, la presencia tendría relación con el regreso de cada una de las partes tras la separación territorial; además del esfuerzo, mediante la escritura, por mantener el diálogo interrumpido entre los amantes a través de la recepción de las cartas por ambas partes.

Para dar cuenta de este objetivo, nuestro análisis se basa en lo dicho, lo vivido y lo sentido (Vovelle, 1985). Es decir, en primera instancia, hacemos referencia a lo que se dice sobre Javiera a nivel historiográfico, considerando el rol de la mujer en el periodo y concretamente la individualización de la mayor de los Carrera, para luego adentrarnos en lo que ella dice o expresa en sus cartas, que en una lectura inicial sería la reconstrucción del espacio circundante desde donde ella enuncia. Luego de esto, se identifican los principales tópicos presentes en sus escritos, para finalmente aproximarnos al cómo ella se expresa y siente, o más bien, cómo se autorepresenta frente a los sucesos, dado que en sus cartas sobresalen notoriamente 
referencias sobre su intimidad, en cuanto mujer o cuerpo que vive, siente y sufre.

Por tanto, nuestro estudio es una lectura sobre Javiera Carrera, la madre de la Patria, a partir de la historia de las mentalidades, concretamente desde un enfoque de historia del cuerpo y las emociones (Le Breton, 1995; 1999). De tal modo, considerando que la principal propuesta de nuestro trabajo es presentar una nueva lectura sobre el imaginario de Javiera Carrera, a partir del enfoque antes mencionado, y en base a las cartas de Javiera, creemos necesario presentar una breve referencia sobre las categorías de cuerpo y emociones, para así dilucidar cómo emerge el cuerpo de Javiera a través de su escritura íntima.

\section{Cuerpo y emociones: consideraciones para el análisis histórico}

La discusión en torno al cuerpo, las formas de vestir, de morir, de alimentarse, de habitar la carne propia, de reír o de llorar no han accedido completamente al estatuto de objeto válido para el interés histórico (Le Goff y Truong, 17). Esta desvalorización da cuenta, en cierta medida, de la persistencia de la concepción del cuerpo solo como parte de la naturaleza y no de la cultura, dejándose de lado la realidad corporal de los protagonistas de la historia en las distintas sociedades históricas. Similar despreocupación encontramos en el cuestionamiento sobre el estado emocional de los sujetos.

Este desinterés por el cuerpo, no es una situación lejana a la realidad historiográfica latinoamericana, transformándose casi en un acto incorrecto hablar de él y las emociones en base al constante énfasis del hacer ciencia, por lo que se ha dejado de lado ambos conceptos o fenómenos como objetos de estudio (Figari y Scribano, 96).

El intento por la resignificación del cuerpo como objeto de estudio para la disciplina histórica, comenzó a gestarse principalmente en la década del 80 en el seno de la Historia de las Mentalidades, aunque ya contase con una mayor tradición en las ciencias sociales, principalmente en la sociología y la antropología (Boito, 2010) ${ }^{4}$.

Pionero en esta senda es Marcel Mauss, quien plantea las "técnicas corporales" como las formas en que cada una de las sociedades impone al individuo un uso determinado de su cuerpo (1979). Es decir, Mauss nos propone un cuerpo que es historia y que permite 
ser historizado en cuanto a sus manifestaciones, ya sean gestos y movimientos, el uso que se le da, metafórico o concreto, y las formas en que se expresa en diferentes medios de comunicación, tanto oral, escrito, visual y sensorial (Araya, 14). Por ello la relevancia de este en cuanto a su papel, sus usos, significados y representaciones en las distintas sociedades históricas.

Un segundo aporte en la valoración del cuerpo, fue lo desarrollado por Norbert Elías quien intentó comprender el cuerpo en un "proceso de civilización", a través del análisis de las costumbres y técnicas corporales desde la Edad Media. Este ejercicio analítico, le permitió dilucidar lo que es el autocontrol de la violencia y la interiorización de las emociones (1997).

Por otra parte, al igual que el cuerpo, las emociones han carecido de un interés de estudio. Esto por ser consideradas como parte del ámbito de lo personal y subjetivo, teniéndose como principal fundamento la tradicional discusión dicotómica entre cuerpo-alma. Aún así, en el contexto de los estudios sobre la centralidad del individuo, se ha relevado el papel de la subjetividad, por lo que será de la mano de las ciencias sociales donde surge el interés por lo emotivo, principalmente lo que es una sociología de las emociones.

El principal objetivo de este enfoque es la explicación de los fenómenos emocionales (Luna, 16). Por ello, el énfasis en analizar las estructuras sociales asociadas a las formas de interacción, las que posibilitan y fomentan determinada emoción; o por el contrario, inhiben o reprimen el surgimiento de estas. El análisis de estas relaciones sociales nos permite caracterizar las emociones según los determinados contextos culturales y las relaciones sociales estructuradas. Ejemplo de esto, es la interacción entre los miembros de una familia, lo cual puede generar ciertas emociones esperadas, susceptibles de ser anticipadas o previstas, es decir, existe una serie de emociones que le son típicas a la estructura familiar de determinado contexto sociocultural. Similar dinámica encontraremos en el discurso amoroso, destacándose emociones como la alegría, el amor, el dolor o la soledad.

$\mathrm{Al}$ ser artefactos culturales, las emociones y los sentimientos son aprendidos por cada uno de los miembros de la sociedad con patrones homogéneos, solo diferenciados básicamente por las características propias del género, edad, rol social, entre otros. En este sentido, 
el análisis y observación de la construcción social de las emociones, evidencia cómo los actores construyen y usan los vocablos y conceptos emocionales, lo que en el caso concreto de nuestra propuesta de estudio, se evidenciaría a través de la escritura de Javiera Carrera. De ahí la persistencia de determinados conceptos relacionados con las vicisitudes que vivió esta mujer, además de estar en relación con los receptores de sus escritos, destacándose principalmente su esposo Pedro con quien desarrolla un diálogo amoroso (Barthes, 1982). Al considerar las emociones como construcciones culturales y su vinculación con las estructuras sociales y al imaginario colectivo, es cuando se puede hacer una conexión entre la sociología de las emociones con la historia de las mentalidades, considerando que ésta última se preocupa de los fenómenos imperceptibles en el devenir de las sociedades, principalmente en la larga duración.

Por tanto, el cuerpo y las emociones son parte de nuestra cotidianidad, de ahí su estudio en un entramado de relaciones con otras dimensiones de lo social, en cuanto su presencia en el imaginario y en la realidad, en la vida cotidiana y en los momentos excepcionales (Le Goff y Truong, 112). Por ello el intento por dilucidar cómo los sujetos se relacionan con sus propios cuerpos y son condicionados o permeados por sus respectivos contextos históricos 5 .

\section{Lo dicho: el mito historiográfico sobre Javiera Carrera}

El primer referente sobre un imaginario en torno a Javiera Carrera a nivel historiográfico, es la obra de Benjamín Vicuña Mackenna Doña Javiera de Carrera: rasgo biográfico, presentada a solo días de la muerte de ésta (1862). Suceso que significó, según el autor, “[el que se haya] apagado una gran vida i desaparecido uno de los actores de aquel drama de gloria i de martirio que redimió a los chilenos como pueblo" (5).

En este escrito se establecen las principales imágenes con que se identifica a esta mujer, surgiendo la denominación de matrona de la Patria. Para fundamentar esta idea, se presenta una genealogía, destacando los principales momentos de su vida. Asimismo, entre estas imágenes se desprende la relevancia de Javiera en cuanto a su rol histórico en el proceso político, siendo catalogada como "la heroína de la Patria vieja, como en la nueva fué la mártir" (Vicuña Mackenna, 
16). Es en esta imagen en donde se aúna un antes y un después en su vida, enfatizándose la cercanía con sus hermanos, la muerte de estos y su regreso del exilio. Relato representado como un escenario oscuro y decadente que es sellado finalmente con la descripción de los funerales de Javiera.

Aún así, la relevancia de esta obra también debe ser comprendida en el contexto de construcción de las historias patrias en el proceso de formación del Estado Nación (Moulian, 1994). Por tanto, su valoración no solo dependerá de la perspectiva del relato, la representación de los acontecimientos y el uso del lenguaje o ciertas imágenes literarias, sino que también implica considerar las lógicas subyacentes a su producción, es decir, en relación a su autor (Foucault, 1973).

La elección de los historiadores del siglo XIX por el tema de la Independencia no solo respondió a un interés intelectual, sino también fue una opción personal, una necesidad de dar cuenta de lo ocurrido. Al ser testigos directos de los hechos, quisieron dejar constancia de lo vivido, lo que ellos consideraron era lo "digno de narrar" (Colmenares, 2006). Para esto, la documentación disponible complementó al testimonio, muchas veces personal, sobre los acontecimientos y quienes le dieron vida, sus protagonistas (Harwich, 535).

En el caso de Vicuña Mackenna, su representación sobre Javiera estuvo en parte determinada por su cercanía a ella. No en vano al final del escrito justifica sus reflexiones, las que "nos arranca solo la espontaneidad de lo que creemos un deber nacional" (42). Si bien quizás nos encontramos frente a una lectura sesgada y subjetiva, el hecho relevante de esta obra radica en ser el primer antecedente sobre la imagen de madre de la Patria y referente en la construcción del mito en torno a ella, retomado y reproducido posteriormente por la historiografía tradicional.

Por otra parte, el discurso historiográfico al enfocarse en la legitimación de la imagen del Estado en formación, también apuntó a la representación de las gestas heroicas y sus máximos exponente, en tanto que posibilitaron la formación de este, a través de minuciosas narraciones sobre los sucesos.

En este sentido, capítulo aparte merece el relato o creación de la "imagen del héroe", como gran exponente de estas hazañas (Colmenares, 85). Tópico en donde se plasmaron las formas básicas de autorepresentación de una colectividad, compendiando además los 
rasgos esenciales, aunque fuesen contradictorios, con que cada pueblo en formación se identificaría. Por ello, el que los héroes del proceso independista hispanoamericano fuesen representados en su rol de alta dirigencia, fortaleza y entereza, ya que no podía existir Patria sin independencia o sin libertad, ni tampoco podía haberla sin héroes (Harwich, 548).

Aún así, en relación a los padres de la Patria, existe un vacío en cuanto al rol de la mujer como madre de la naciente Nación. Vacío que en muchos casos ha sido sustituido por las imágenes de advocaciones marianas, en tanto patronas y elementos generadores de identidad en el proceso (Soto, 2009) ${ }^{6}$. De este modo, frente a la ausencia de una madre de la Patria o heroína, Javiera ha sido valorada en el rol de ser la hermana de y no en un accionar concreto e individual a lo largo del proceso, adosándole solamente la connotación de madre para ser homologada a los héroes, pero siempre bajo una actitud pasiva, propia del ser mujer en el periodo.

Frente a la lectura dominante sobre el proceso, y la participación androcéntrica, resulta imperativo reivindicar el rol de la mujer en este acontecimiento ${ }^{7}$. Tarea inconclusa, pero que en los últimos años ha contado con importantes aportes por hacerla visible y su efectiva participación, destacando el papel jugado por ella en los sucesos, emergiendo así un accionar alejado de la pasividad creada por el discurso decimonónico (Franco, 18). Invisibilidad o papel ambiguo de la mujer que por lo demás tiene sus antecedentes en el periodo colonial:

La imagen de la mujer ideal en los sectores cercanos al poder colonial, es aquella que muestra recogimiento, recato y discreción frente a su entorno familiar y social; disciplina en el cumplimiento de las obligaciones que impone la religión. Además de la asistencia frecuente a la rutina de eventos religiosos (Muñoz, 2005).

De tal modo, silenciadas, olvidadas, reducidas a una actitud y participación política pasiva, el ser mujer en la Independencia estuvo subordinado al rol activo del hombre, careciendo de mayores opciones de visibilidad, aparte del espacio doméstico o el mundo conventual (Grez, 26). 
Aún así, a pesar de la persistencia del sistema de valores que determinó el deber ser de la mujer en el periodo, al trazar una cartografía a lo largo del territorio hispanoamericano, y haciendo escala en cada uno de los países en sus respectivos procesos independistas, emergen tras los grandes héroes de la causa, mujeres que aportaron a ésta ya sea a través del compromiso activo en la toma de las armas, usando sus encantos en labores de espionaje y correo, o aportando asistencialmente con su patrimonio, o prestando compañía a los héroes ${ }^{8}$.

En este último punto, más que la reproducción de los nombres y sus respectivas actuaciones, lo relevante es dilucidar cómo se relacionó la mujer con el proceso independista, desde lo que se deseaba para ella en la sociedad y el cómo esta se hizo partícipe de los hechos, puesto que de una $\mathrm{u}$ otra forma fue permeada por el debate ideológico del contexto, tanto de fidelidad o separación del Antiguo Régimen (Godineau, 38).

Con respecto al cómo la mujer se hizo parte del proceso, y lo que se esperaba que realizara, su visibilidad principalmente estuvo limitada a su categoría social y a los espacios en donde transitó. Sin embargo, a pesar de no ser partícipe directa de las discusiones del ámbito político, pudo acceder a otros espacios de debate, mezclándose en la esfera política de un modo concreto y simbólico. Así fue que transitó entre el espacio público y el privado, dualidad concretada en el salón, como espacio privado por ser parte de la vivienda, y público o de socialización, al ser el lugar de reencuentro entre las personalidades públicas. Es ahí, y específicamente en la tertulia, en donde la mujer fue organizadora de la vida social, estableciendo contactos entre políticos, comerciantes e intelectuales, además de desarrollar estrategias para el intercambio de un ideario político y cultural. Si bien estas reuniones no pueden ser equiparadas a las del Viejo Continente, han sido valoradas como las "academias revolucionarias en cuyo seno se agitaron las grandes y fecundas ideas que realizaron todos los prodigios de la independencia" (Grez, 20).

Hasta el momento hemos esbozado el contexto en donde se movilizaron las mujeres durante la Independencia, desde su opción o postura frente a los hechos en relación al debate en la sociedad, o el cómo se les hizo partícipe de dicha discusión ideológica. Postura que incidió en el cómo se hizo parte de los hechos, cómo los vivió y 
los malestares que sufrió. Esta reconstrucción tiene por objetivo ser el telón de fondo en donde comprenderemos el rol de Javiera en el proceso, ya que ella transitó en los ámbitos y espacios antes señalados. Asimismo, debemos señalar que hay ciertos aspectos en cuanto a su individualización, que la hacen ser distinta al resto, por ello la relevancia de su estudio más allá de la reproducción de lo dicho por la historiografía.

Como caso concreto entre las mujeres de la Independencia, Javiera se destaca como gran exponente de una participación activa, pero ligada a su familia. Imagen enaltecida por sobre las otras mujeres del periodo, pero que como vimos anteriormente dependió en gran parte del discurso construido por Vicuña Mackenna, además de los apelativos de ser hija, esposa y hermana de, que circundan a su imagen.

Nacida en una de las familias de mayor renombre en la elite criolla del periodo, fue la hija mayor y única mujer del núcleo. Desde pequeña fue criada según su estatus en la hacienda familiar de San Miguel, en El Monte. Siendo muy joven se casó con Manuel de la Lastra con quien tuvo dos hijos, pero de quien quedó viuda tempranamente. Tiempo después vuelve a casarse, esta vez con el funcionario real Pedro Díaz de Valdés con quien vivió los momentos más convulsionados de su vida.

En el recorrido por la vida de Javiera, un momento determinante es a inicios del proceso independista, en donde adquiere un destacado protagonismo en los hechos, al prestar consejo y compañía a sus hermanos, principalmente a José Miguel quien llegó a gobernar en 1812. Pero tiempo después, y tras las maquinaciones de los opositores a este y a sus ideas revolucionarias, sumado al avance de la reconquista española, la familia Carrera pasa a conformar el gran número de perseguidos, encarcelados o exiliados por ser contrarios a los ideales de fidelidad a la corona española. Es por eso que Javiera decide acompañar a sus hermanos y refugiarse en Argentina, desconociendo las vicisitudes que deberá sobrellevar al otro lado de la Cordillera. Es en este momento donde desarrolla una amplia escritura, mencionando tanto su postura sobre los sucesos de carácter político desde el exilio, así como las vivencias y su sentir.

Inmersa en un contexto deplorable, lejos de su familia y alerta a los sucesos que ocurren en su país, Javiera debe enfrentar en la 
soledad el fusilamiento de sus hermanos con lo que gran parte de su vida se esfuma. Luego de esto, y solo tras la caída de O’Higgins en el gobierno, Javiera vuelve a su Patria. Tras su regreso al territorio chileno, ella se vuelca al espacio íntimo o doméstico en su hacienda en El Monte, sin volver a tener una mayor visibilidad en el ámbito social o político. En el silencio de su hogar, muere en agosto de 1862.

La anterior referencia a los rasgos biográficos de Javiera, más que ser una reproducción de lo ya dicho, nos permite dilucidar que el apelativo "de" fue algo que pesó mucho en ésta, ya que desde el apellido fue determinada parte de su vida. Situación que incluso menciona en una de sus cartas dirigida a su esposo, que "[poseía] el pecado de ser Carrera". Asimismo, esta es la principal representación sobre Javiera, construida por Vicuña Mackenna y perpetuada por la historiografía tradicional.

\section{Lo vivido: escritos de una mujer de elite. Una aproximación al epistolario.}

Entre los mecanismos o espacios de socialización de las mujeres con los representantes de la sociedad a inicios del siglo XIX, se destaca el salón y la escritura, ésta última en su materialización de la carta. De tal modo, ambos fueron "los espacios culturales femeninos por excelencia, ya que regularon y canalizaron la palabra de la mujer" (Arambel, 20).

La carta en cuanto práctica discursiva, cuenta con ciertas características que harán que sea esta y no otra cosa9 . La principal de éstas, es la posibilidad de establecer una relación en donde los participantes hagan o vuelvan presente a un otro a través de la construcción e interpretación del contexto social.

Un primer referente de esta escritura femenina en el contexto chileno, lo encontramos en el periodo colonial, aunque circunscrita especialmente al espacio conventual, por lo que los temas tratados remiten particularmente a la relación entre las religiosas con la divinidad $^{10}$. Posteriormente en la Independencia, las mujeres transmitieron a través de estos escritos una visión femenina del contexto en el que estaban inmersas, dando cuenta de nociones sobre la identidad nacional y el lugar de estas en las nuevas repúblicas (Chambers, 2005). 
Este tipo de correspondencia se diferencia de la literatura epistolar al carecer de una intencionalidad literaria y su posible publicación, al ser el resultado de la espontaneidad de sus autoras quienes quisieron plasmar su inmediatez, transformándose en el medio privado propicio para la transmisión, tanto de noticias públicas como de secretos íntimos. Por otra parte, se puede considerar al género epistolar como una de las primeras formas de autorepresentación de la mujer, al esbozarse un retrato de ésta en donde se define, en tanto a un antes y a un después en relación a su sentir (Arambel, 16).

Con respecto al epistolario de Javiera, en primer lugar este es un conjunto de cartas y no un corpus concreto, por lo que principalmente se identifica a ella como emisora. Sin embargo, al considerar las respuestas a estas, cambia la finalidad de ser sólo leída y respondida, estableciéndose un diálogo o comunicación entre dos partes ${ }^{11}$. En este caso, son escritos dirigidos en su mayoría a su marido, aunque también existen hacia su padre y a su hermano José Miguel, entre otros familiares. Esto demuestra un diálogo entre ambas partes, ya que en muchas de las introducciones a estos escritos se hace referencia a cartas recibidas anteriormente, además del énfasis por no recibir respuestas, lo que es una constante por parte de ella, apelando casi a un reclamo.

Un ejemplo de esta interacción con su esposo, es cuando se enteró del matrimonio de su hija, por lo cual expresa molestia al no ser consultada por su consentimiento para tal toma de decisión. Otro ejemplo es cuando encarga a su esposo que vele por sus pertenencias, quien luego le responde que ha realizado averiguaciones y que está recuperando las cosas enumeradas por Javiera, lo que describe detalladamente en la carta de respuesta.

Al pensar la carta como un discurso, su estructura y finalidad, también se debe considerar que la reconstrucción del contexto en el escrito está mediado por el lugar en donde se encuentra Javiera como sujeto enunciante. Según esta perspectiva, es posible reconstruir un itinerario desde donde escribe, adoptando la metáfora del viaje, y así una delimitación de los lugares y el cambio en los tópicos referidos, teniendo en cuenta que lo subyacente a esta práctica es la lucha por la interpretación de la realidad que emerge desde la escritura íntima (Franco, 1994). 
También es significativo destacar que Vicuña Mackenna fue el primero que accedió a estas cartas y las utilizó como fuente documental para sus escritos, de ahí su valoración:

La redaccion de todas estas piezas acusa, por otra parte, la clara intelijencia de de su autora: es una diccion precisa, sostenida, palpitante, i sobre todo llena de calorosa espontaneidad, sin rodeos de engaño ni esos mil artificios de estilo i de hechiceras mentiras que son el arte epistolar de las mujeres, solo a veces el humor travieso, que hizo a los Carrera tan célebres casi como sus grandes infortunios, se escapa entre los ayes de la pena en las pájinas íntimas de la ilustre desterrada (24).

\section{El itinerario de Javiera: entre la ausencia y la presencia en su escritura}

Es complejo delimitar la fecha de inicio de estas cartas. Aunque un punto de inflexión es el Desastre de Rancagua por la caída del gobierno de su hermano José Miguel, el avance de los realistas y el que los patriotas con ideales independistas fuesen perseguidos o condenados al exilio. Por tanto, este hecho marca un antes y después en la travesía o vida de Javiera.

Pero antes de este suceso, y como primera etapa de este itinerario, están las cartas dirigidas a su marido, quien tras el primer avance de las ideas revolucionarias es excluido de su cargo en el gobierno colonial, por lo que viaja a España para su restitución. Debido a esto, Javiera por segunda vez se encuentra en soledad, tras lo que había sido la pérdida de su primer marido, por lo que teme que una vez más el destino esté en su contra. Sentimiento de incertidumbre y dolor, que son plasmados desde el primer instante de lejanía con su esposo:

Desde que me separé de ti no sé qué cosa es reposo, un cierto movimiento extraordinario me tiene pensando en el imposible de oírte hablar; cruel separación es ésta por cierto. La confusión que reina en mí no me deja continuar ésta y hazte cargo sólo del entrañable amor ${ }^{12}$. 
Entre los temas tratados en este primer conjunto de cartas se destaca lo político, ya que Javiera está constantemente informando los sucesos acaecidos durante la lejanía a su esposo. Ejemplo de esto, es cuando cuenta que "la ciudad está muy trastornada por la orden de prisión dictada por el gobernador a José Antonio Rojas, Juan Antonio Ovalle y Bernardo de Vera y Pintado por contar con ideales de independencia, por lo que se dictaminó que a todo sujeto que hable de que España está en mal estado o quieran criticar al gobierno, habiendo dos testigos le echen garras y los remitan bajo partida de registro"13. Una segunda alusión política, es cuando menciona que ha sido aconsejada para convencer a su esposo para que retorne al país ya que Antonio García Carrasco, último gobernador español, había dejado el mando del gobierno.

Otra temática que sobresale en este primer conjunto de cartas, es la manifiesta preocupación de Javiera como madre y esposa, incluso al punto de enviarle un colchón y mantas a Díaz de Valdés, junto con indicaciones como el "no te fatigues y para excusar esto que te lleven a hombros"14. Además, le envía a un arriero con sus cartas, quien también lo cuidará en su travesía ${ }^{15}$.

Por tanto, esta primera etapa del itinerario de Javiera se caracteriza por la lejanía de su esposo, a quien informa y orienta a lo largo de su viaje. Además se destacan las primeras alusiones de un estado de melancolía en ella. Esto se manifiesta en el constante énfasis por tener noticias de su amado, considerando además que en esa fecha estaba embarazada, lo que aumentó su sentimiento de soledad, sentir aplacado cada vez que recibía noticias de él:

Figúrate cómo estará este pobre corazón con la triste memoria de nuestra separación; pero, hijo, si la distancia nos separa, sabe que mi voluntad está en todos momentos contigo, deseándote las más completas felicidades, sin que yo pueda tenerlas hasta no verte ${ }^{16}$.

De tal modo, la máxima manifestación de este clima de pesimismo y dolor expresado por Javiera, es la frase "todo es trastorno en este valle de lágrimas" ${ }^{17}$. Enunciado que sintetiza la forma en que se autorepresenta a través de sus cartas. Imagen o sentimiento de melancolía y dolor que trascenderán en el tiempo, incluso aumentando en el momento en que sea ella quien esté en el exilio. Finalmente, 
esta primera separación con su esposo, que transcurrió entre 1810 y 1813, llegó a su fin tras un decreto que permitió el regreso de Díaz de Valdés, y que además fue informado oportunamente por su esposa $^{18}$.

La segunda etapa del itinerario, y quizás más fascinante a los ojos de sus contemporáneos, es el exilio de Javiera. Tras la derrota de Rancagua, ella temió las persecuciones del ejército realista por lo que se refugió en la hacienda de Chicauma en Lampa. Pero al no sentirse segura traspasó la cuesta de Chacabuco y se asiló en la villa de los Andes, según expresa en una de sus cartas. En ésta también comenta que se dirigirá a Mendoza acompañada por su hijo menor Pío. Este avatar es recreado en el escrito en donde además manifiesta un cierto malestar hacia su esposo:

Dices que las mujeres no tenemos opinión, tengo el pecado de ser Carrera, por esto habrán despedazado mi casa (...) Ahora tú me harás la justicia de creer que paso de dejarte a ti y mis amados hijos, no por preferir otros a ustedes, como me has repetido con injusticia muchas veces, sino por la necesidad que me obliga el destino ${ }^{19}$.

Si bien en esta carta existe un tono de cierta molestia, esto se debe principalmente a la situación en la que está inmersa, el que su familia sea perseguida y que luego tenga que partir al exilio. Asimismo, esta carta tiene su correlato en una segunda parte, ya emprendido el viaje:

Nunca creí sería tanta tu indolencia en los graves apuros que sufrimos desde la Aconcagua (...) ¿qué han hecho las protestas que me hacías contando con que una mujer no se mezcla en gobierno? Si tuve influjo todo fué a favor de ustedes. ¿No me asegurabas que verías al señor Osorio (Mariano) y que en mi casa no habría novedad $?^{20}$

Como se observa en el extracto de esta carta, Javiera es crítica con su marido al no tener noticias de él. Incluso le menciona los contactos e influencias que ella realizó durante su lejanía para concretar su regreso. Además señala que solo por rumores se enteró de la prisión de su padre y de su envío a la Isla Juan Fernández. Frente a este 
hecho, Javiera es confrontacional incluso con su marido Pedro, ya que su padre era de la misma tendencia de él, "sarraceno" o realista, por lo que no logra comprender la prisión de éste: “(...) así como por ti el propio mi padre y yo mil veces les hemos servido", en alusión al gobierno español. También enfatiza en ser informada sobre los sucesos que ocurran, ya que en caso de continuar los problemas regresaría por su padre y sus bienes, pero para lo que cual necesitará de un pasaporte dado por Osorio y "que tú u otro amigo viniese hasta el pie de la Cordillera" a recibirla.

Otro de los temas presente en esta primera carta durante el exilio en Mendoza, es el relato de la llegada de Javiera junto a sus hermanos, ya que tuvieron un "terrible" recibimiento al ser estos acusados de robo, detenidos y escoltados hacia Buenos Aires. Situación frente a la que demuestra mayor malestar, al punto de señalar "cómo estará el Guacho, Maquena, Yrrisarri", en alusión a que estos estarían tras el hecho ${ }^{21}$. Asimismo, en ésta habla del contexto deplorable en el que está inmersa, careciendo incluso de dinero, por lo que es necesaria la respuesta de su esposo. Frente a esto, una vez más resalta su precaución de mujer, ya que si su esposo no cuenta con el dinero para el envío, le indica cómo conseguirlo, recurriendo a sus amistades y "que no los olviden en la desgracia y otros endeudados, [y que] no descuides esto para no mendigar"22. Finalmente, en esta carta por primera vez menciona que se encuentra muy enferma por lo que no puede continuar escribiendo.

Si bien Javiera emprendió su travesía tras la derrota en Rancagua, en la respuesta de su marido, él le reprocha su decisión de viajar, ya que "mucho ha perjudicado, Javierita, tu precipitada resolución de pasar la cordillera contra lo que teníamos dispuesto de común acuerdo" 23 . Esto debido a una falsa noticia durante su estadía en la villa de Los Andes. Otra particularidad de esta carta es la manifestación explícita de la tendencia ideológica de Díaz de Valdés al momento de referirse a Mariano Osorio, gestor de la Reconquista Española, como "muy amable general en jefe", quien había otorgado un permiso para el regreso de Javiera. Sin embargo, debido al clima de crisis interna en el territorio, junto a las dificultades de comunicación, esto no se concretó.

Entre las noticias que Díaz de Valdés entrega a su esposa a lo largo del tiempo, en 1816 menciona el indulto dado por el rey Fernando 
Séptimo a los confinados a la Isla, entre los que estaba el padre de los Carrera, además de la devolución de sus bienes embargados, los que fueron recuperados y puestos bajo encargo de su marido ${ }^{24}$.

Un año después, en carta fechada del 17 de febrero de 1817, Pedro cuenta a su esposa la victoria en Chacabuco, por lo que "basta de correr cortes cuando ya tienes paso franco para trasladarte al patrio suelo", por lo que pronto ella podría volver a su Patria ${ }^{25}$. Además, menciona el nombramiento de O'Higgins como Director Supremo.

Así como Pedro informa a su esposa sobre la situación del país, también cuenta de los rumores en el territorio chileno sobre la llegada de José Miguel desde Norteamérica con armamento, y que sería acompañado por Javiera en su regreso al territorio, lo que considera sería imposible sabiendo de la llegada de la expedición libertadora a Chile. Por ello enfatiza en tener pronto noticias de ella ${ }^{26}$.

Tiempo después, mientras Javiera está en Mendoza, se enteran en Chile de la condena a muerte para los hermanos Carrera, lo que provocó un gran pesar en el padre de estos, tal como comenta Pedro a su esposa. Debido a esto y frente al peligro inminente, la insta a tener aún más cuidado con la correspondencia:

Repito, mi vida, que no dejes de escribir correo alguno porque yo hago lo mismo y es el único consuelo que podemos tener en nuestra violenta y larguísima separación. Quiera Dios darnos vida para restablecer aquella sociedad que en un tiempo era dechado de las de esta clase, conociéndonos por los esposos católicos. Te aseguro (y no creo que lo dudes) que nada más apetezco en este mundo, y serías tú muy ingrata si no tuvieses igual sentimiento; pero estando a lo que expresas en las tuyas, me persuado procedemos de conformidad. Dirás que soy difuso, pero es porque hablo contigo $^{27}$.

Frente a la muerte de sus hermanos y la distancia con su esposo, Javiera expresa:

[que] todos son más felices que yo. Vivo ya desesperada en la ansiedad de que llegue este día para mí, pero creo que primero que me dejen libertad me muero, y lo peor es que no alcanzo un ápice de conformidad ${ }^{28}$. 
Este clima de incertidumbre al no estar con su amado, junto a la pérdida de sus hermanos, lleva a Javiera a ser aún más expresiva e incluso trágica en su sentir: "esta vida no es apetecible por cierto; sin patria, sin padre, sin ti, sin mis hijos, sin mis hermanos". Pesar al que se agrega el no contar con dinero para subsistir ya que todo lo que tenían fue invertido en sus hermanos quedando "(yo) tan miserable como antes de la reconquista". Desazón de Javiera que es aún más explícito en las siguientes cartas dirigidas a su esposo:

Si no fueran desatendidas mis súplicas no dejarías pasar correo sin escribir, pero en todo sigue mi vida de ansiedad (...) No soy injusta ni fulminante, me sobran motivos de desesperación, ustedes en su país, con bienes, no mandan dinero, y yo, en tierra extraña, sin el menor recurso, debo vivir de la providencia, que esta cuide de todo ¿no es verdad' Justicia, no desnaturalizarse, te encarga tu paciente y desgraciada e inolvidable ${ }^{29}$.

Posteriormente, tras la ejecución de José Miguel ella continúa en el exilio. En 1822 se traslada a Montevideo manteniendo correspondencia con su esposo, aunque el contexto y el sentir son disímiles a los inicios de su exilio, tal como lo recrea en el siguiente escrito:

Tomar leche de burra que me va probando bien, nada omito hacer para sobrevivir a los males que me han reducido a este estado, para sólo vivir para los que me han dejado en este mundo, tú no me escribes y de este silencio resulta mi gran inquietud ${ }^{30}$.

En estas cartas ya comienza a visualizarse la intensión de Javiera por retornar a su tierra, tal como se expresa en el siguiente extracto: "ya te he dicho yo no deseo otra cosa que la vida privada y sólo la compañía tuya y de mis hijos, (...) vivir tranquila en mi San Miguel ¿cuándo llegará este día tan deseado?".

La tercera etapa y final del itinerario de Javiera, se concreta con su regreso tras la renuncia de O'Higgins al gobierno. Retorno que comienza mucho antes de este hecho, pero desde una forma simbólica, ya que la ejecución de los hermanos Carrera dejó grandes heridas en la hermana mayor de la familia, sobretodo el fusilamiento de José Miguel. Este hecho fue el que determinó su retorno, aunque señala que "ya no tiene nada que hacer para volver a su Patria, que ésta ya 
no es su Patria", en alusión a la pérdida de sus hermanos y al fracaso del proyecto político por ellos ideado.

La ruta de regreso es totalmente distinta a la de un comienzo, no viaja por tierra sino que por mar. Antes huyó por un ideario para su Patria junto a sus hermanos, ahora vuelve a ver el resultado del proyecto concretado por el contrincante de sus hermanos, O'Higgins. Vuelve a su Patria, pero sola; los restos de sus hermanos yacen en el territorio argentino. Su refugio es la antigua hacienda de San Miguel, lugar que la vio crecer y que fue testigo de los incipientes planes de libertad por parte de sus hermanos. Tras diez años de ausencia en el territorio chileno vuelve a habitar aquel lugar campestre con su marido e hijos.

No obstante, tiempo después es golpeada una vez más por el destino, primero con la muerte de su esposo, y luego con la de su hijo mayor Pío, a causa de un accidente. Pero antes de la muerte de éste, en 1828 Javiera le encomienda la tarea de gestionar el traslado de los restos de sus hermanos fusilados desde Argentina:

\footnotetext{
Nunca dudé mi hijo sufrirías martirios muy punzantes a tu sensible corazón pero eres mi hijo e hijo verdadero porque te interesa lo que a mí y te destiné para levantar de un suelo extraño a mis mártires amados y que sólo en algún día me reuniré a ellos ${ }^{31}$.
}

Finalmente, el traslado de los restos de los hermanos Carrera y su posterior sepultura, significó el último momento en donde Javiera se hizo visible al mundo exterior, social y político, hasta su muerte.

\section{Lo sufrido: la autorepresentación del cuerpo y las emociones en Javiera Carrera}

La escritura privada permite entrar al ámbito de la intimidad, ya sea en su expresión de diarios, epistolarios o cartas. Al explorar estas representaciones no se trata de reconstruir anécdotas o hechos curiosos de una vida privada que ha sido descrita en estos escritos, sino más bien, dar cuenta cómo se percibieron estas experiencias en las mentalidades, "esto es, más que la vida privada la actitud ante la vida privada, y no sólo la narración, sino también los silencios: no sólo el discurso, sino también su laconismo o su ausencia" (Foisil, 
331). A través de estos escritos "las mujeres revelan sus intereses individuales, familiares y políticos al tiempo que dan testimonio de las costumbres y de las opiniones de la mujer" (Arambel, 20).

La carta encierra en sí misma la promesa de una revelación e intimidad cuya privacidad es transgredida por el acto de la lectura, por quien es su receptor y quizás motivo de inspiración. Relación comunicativa formulada en términos de un yo que enuncia a un tú que lee. Este proceso se caracteriza por una "presencia ausente", tanto del destinatario en el momento de su escritura como del emisor en el momento de la lectura. Cartas que dan cuenta de la presencia y despliegue de un yo que ejerce su poder sobre el interlocutor ausente. Ausencia de otro, que es reemplazada por su reconstrucción imaginaria en la escritura, el $t u ́$ deseado cuya voz se hace oír.

En este sentido, la carta de amor al ser la expresión del deseo, conlleva a la respuesta, obliga al otro a responder. De lo contrario, la imagen del ser amado (a) se desvanece o es sujeta a cuestionamiento (Barthes, 52).

Por otra parte, el género epistolar, posibilita establecer una comunicación diferida en el tiempo y entre espacios distintos (Soto, 1996, 154). Correspondencia entre dos personas a lo largo del tiempo que se manifiesta como una interacción verbal. Por ello, la existencia de marcadores de tiempo y el lugar de la emisión, apelaciones al destinatario -mi muy querido(a)-, referencias a comunicaciones pasadas, la identificación del emisor y de los destinatarios mediatos, así como la petición de eventuales comunicaciones a futuro (Soto, 1996, 155).

De tal modo, cabe señalar que estos elementos son parte fundamental del epistolario analizado, en cuanto a la finalidad y estructura del texto, que en el caso de Javiera da cuenta de la autorepresentación de su sentir en un determinado marco temporal y espacial. Es por ello que la lectura a esta fuente debe ser en un sentido amplio y no sólo centrada en un primer nivel de análisis literal, lo que sólo nos remitiría a esta mujer en un rol de enunciante, sino más bien, debe ser comprendida como sujeto que establece un diálogo con su destinatario.

Ejemplo de esta interacción se observa en la forma en que se dirige a su marido, ya que constantemente se visualiza una postura de reclamo hacia él, principalmente al no tener noticias o respuestas a 
sus escritos, por ello denominarlo incluso como indolente. Sin embargo, al parecer esta actitud es mutua, ya que su marido también apela el no tener noticias sobre ella. Esta situación se visualiza tanto en la primera etapa, cuando él está lejos de la Patria, y luego cuando ella está en el exilio. Aún así, estos reproches por la carencia de noticias entre ambos amantes, también dan cabida al lamento y a la exaltación del anhelo del reencuentro, una de las principales constantes en los escritos de esta mujer.

A lo largo de sus cartas, Javiera da cuenta de los momentos que debe enfrentar y que van configurando su persona. En un primer momento es cercana al gobierno, pero luego es perseguida teniendo que enfrentar múltiples avatares, tanto en lo circunstancial del contexto así como en lo emocional. Es durante el exilio, en donde debe afrontar las injurias y maquinarias en contra de sus hermanos. Observa todo lo que ocurre a su alrededor, pero ya no participa activamente frente a los sucesos o prestando consejo a sus hermanos. Más que consejo, brinda ayuda y soporte, hasta el momento de la muerte de estos.

Tras su regreso al país, Javiera entra en un estado de total invisibilidad del escenario social, y más aún político. Se vuelca a la vida familiar en la hacienda de su familia, dejando atrás las reuniones sociales en donde se planearon los proyectos independistas, en donde se pensó la nación, y en donde ella fue parte de aquel ideario libertario.

En esta etapa se visualiza en ella una total ausencia al estar inmersa en la melancolía, lamento o dolor. Emociones que si bien fueron latentes a lo largo de sus escritos, ya desde la estadía de su esposo en el extranjero, se muestran aún más visibles durante su estadía en el exilio. Ausencia en el ámbito social, interrumpida solamente cuando debe realizar los preparativos y trámites para la expatriación de los restos de sus hermanos. Luego de esto, ella vuelve nuevamente a la ausencia, volcándose a su espacio privado e íntimo, hasta el momento de su muerte.

A través de las cartas como soporte material, se visualiza cómo Javiera se autorepresenta, en tanto cuerpo que vive y siente en un determinado momento de su vida. Por ello nuestro interés de rescatar el simbolismo del cuerpo y las emociones, principales tópicos 
presentes en sus escritos, algo que por lo demás no es considerado en el discurso historiográfico en torno a ella.

En primer lugar, la categoría cuerpo debe ser entendida en cuanto a su proceso de construcción, considerando las representaciones sociales en torno a este, ya que la concepción actual de este, conlleva a un cúmulo de nociones desarrolladas a través del tiempo. Es decir, las imágenes sobre el cuerpo han sido permeadas o están relacionadas con procesos y transformaciones sociales según determinados contextos históricos.

Un ejemplo de este proceso, y antecedente para nuestro estudio, es la concepción del cuerpo femenino durante el periodo colonial en Chile, la cual es muy distinta en el siglo XIX, en el contexto de Javiera. En el primer periodo mencionado, nos encontramos con un cuerpo de mujer inserto en el espacio privado, o su hogar, dedicada al ámbito familiar; mientras que en segundo lugar encontramos a una mujer situada en el espacio religioso o conventual, entregada a Dios. Al estar estos cuerpos insertos en espacios delimitados, se explicaría, en cierta medida, el rol pasivo de la mujer en la sociedad colonial.

En contraste a este cuerpo sometido, en el periodo de la Independencia la mujer estuvo mediada por su contexto, concretamente la crisis política interna, por lo que se hace partícipe de la discusión ideológica. Además, lentamente transita entre el espacio privado hacia el público, proceso que hemos referido anteriormente.

En el caso de Javiera, la forma en que representa su cuerpo es a través de la referencia a la enfermedad, por ello la constante de que se encuentra enferma y no cuenta con fuerzas ni siquiera para continuar escribiendo. Enfermedad también aludida en relación a su esposo, ya que en un momento se entera que él está enfermo, por lo que le envía instrucciones de cuidado.

Si bien esta mujer se autorepresenta como un cuerpo enfermo, descrito según los síntomas o males que la aquejan, en estrecha relación a las vicisitudes que debe sobrellevar, la principal representación de su cuerpo es a partir de las emociones. Es su cuerpo el que somatiza el dolor por la lejanía y por los sucesos que marcan su vida, la lejanía de su esposo, el exilio, la muerte de sus hermanos, la soledad de estar en un territorio al que no pertenece.

Cabe señalar que el cuerpo al poseer múltiples expresiones, entre ellas la gestualidad, permite ser leído, pero también es el reservorio 
de una intimidad sofocada que sólo tiene expresión a través de manifestaciones materiales o inmateriales. Al primer tipo correspondería la escritura íntima, o en este caso, las cartas de Javiera, mientras que lo inmaterial correspondería a las emociones por ella expresadas a través de su escritura.

Por otra parte, las expresiones orales de los sentimientos al no ser sólo fenómenos psicológicos o fisiológicos, sino que también sociales, llevan implícitos un carácter de espontaneidad, es decir, frente a determinados sucesos o agentes emergerán desde el interior de la persona. En este tipo de expresiones orales, o inmateriales, podemos comprender el llanto (Mauss, 81).

El llanto o las lágrimas, según Mauss, representan múltiples usos, e ilustran el carácter convencional de mímicas o manifestaciones corporales (126). Lágrimas como expresión de las emociones que muchas veces son indecibles verbalmente; como forma de demostración de un estado anímico, lágrimas de alegría, de tristeza, de desconsuelo o frustración.

En las cartas de Javiera, estas son un tópico o expresión constante, como representación del dolor que atraviesa su cuerpo, como forma de hacerlo "hablar" y que esa emoción o sentimiento sea escuchado, leído y comprendido por su interlocutor. Este tópico se destaca principalmente en los escritos dirigidos a su esposo. Son lágrimas entre amantes, de dolor frente a la lejanía, de la imposibilidad de cercanía entre ambas partes (Lutz, 1999).

Si bien las lágrimas serían la expresión de un cuerpo doliente que está en el exilio, lejos de su Patria, de su familia, de su amante, su reiterativa referencia también daría cuenta de un constante estado de melancolía que envuelve a Javiera (Bartra, 2001). Los acontecimientos que debe sobrellevar durante su exilio no se alejan de ser una situación en desmedro para cualquier mujer, pero Javiera expresa que se siente inmersa en un "valle de lágrimas", no ve salida a sus sufrimientos, todo es oscuro. La lejanía es más fuerte que su interés por volver a su Patria.

Finalmente, esta representación, o más bien autorepresentación, que emerge desde la escritura íntima, difiere totalmente de la imagen construida por la historiografía tradicional, ya sea en cuanto a un rol pasivo o activo de Javiera Carrera. A través de las cartas emerge un cuerpo que vive y siente los acontecimientos de su contexto 
histórico. Es un cuerpo que habla a través de su escritura, que es crítica frente a los hechos políticos, pero que también deja hablar a su interior, desde un posicionamiento de hija, hermana, madre, esposa y amante a $^{32}$.

\section{Comentarios finales}

Hace unos años atrás y con el objeto de la celebración del Bicentenario de la Nación, surgió una nueva tendencia revisionista sobre el acontecimiento, que a través de publicaciones, jornadas, editoriales, entre otras manifestaciones, repensó una vez más el proceso de Independencia, ya sea desde distintos enfoques investigativos o fuentes documentales. Esto permitió la valoración de "nuevos" sujetos o actores sociales no considerados relevantes en el proceso por la historiografía oficial, pero que sin duda jugaron un determinante rol junto a los grandes héroes, aportando a la causa. En este ejercicio de relectura podemos insertar nuestra propuesta de estudio.

Si bien hemos abordado a un "personaje" concreto, Javiera Carrera, en cuanto imagen construida y perpetuada por la historiografía tradicional, y que no presenta cuestionamiento alguno, con el tiempo han aparecido imágenes complementarias al discurso oficial, en el intento por visibilizarla en el espacio público, inmersa en la discusión y accionar político.

No obstante, según nuestro parecer, aún queda pendiente la tarea por humanizar a los héroes de la Patria, tanto el caso de Javiera, trabajado concretamente en este estudio, al igual que a otros sujetos de nuestra historia, más allá de las grandes construcciones decimonónicas, en su visualización como personas de carne y hueso que al estar insertos en un determinado contexto, y desde su posicionamiento social, tuvieron que enfrentar las vicisitudes de distintas formas, ya sea desarrollando mecanismos de subsistencia y resistencia frente a las inminentes transformaciones políticas o, de lo contrario, siendo proclives a estas.

En base a esto, la historia de las mentalidades nos permite realizar nuevas entradas a los procesos o a estos personajes-héroes, además de la valorización de otro tipo de fuentes documentales, tal como lo propuesto en este estudio, concretamente desde la historia del cuerpo y las emociones y la lectura de las cartas, o epistolario, 
como fuente documental (Burke, 1993). Es así como este enfoque y este tipo de fuente nos permitió sistematizar en otro nivel de análisis los escritos de Javiera, según los tópicos más recurrentes en estos, y más allá de una lectura de carácter político o reivindicativo, que por lo demás es un gran avance en la resignificación de su persona (Ulloa, 2010).

Como se mencionó, el objetivo de este estudio fue la reconstrucción del repertorio simbólico operante sobre el cuerpo de Javiera Carrera, en cuanto mujer inmersa en el contexto independista chileno, y así dilucidar cómo se autorepresentó a través de su escritura, en donde destacó el tema del cuerpo y las emociones. Para este objetivo, en primer lugar nos aproximamos al imaginario en torno a ella, concretamente el discurso historiográfico, en donde más que establecer las principales imágenes, se observó que esto respondió a las convenciones de la época en cuanto a la construcción de las Historias Patrias y no como una forma particular de representarla (Colmenares, 2006). Asimismo, resultó necesario referirnos al rol jugado por la mujer en el periodo, los espacios en donde se desenvolvió y los mecanismos que desarrolló, para luego la individualización de Javiera. Esta entrada nos permitió abordar el epistolario y sus particularidades, en cuanto mecanismo para la transmisión de información sobre los sucesos, y como material para plasmar la intimidad de esta mujer y el rescate de sus emociones.

A través de este análisis, y la reconstrucción del itinerario de las cartas de Javiera, se identificaron los principales referentes representados en su escritura, lo que permitió dar cuenta de cómo se autorepresentó en un contexto determinado de convulsión políticasocial, ya sea desde forma crítica o activa, versus la representación de su intimidad en donde emergió un cuerpo enfermo, mediado por el dolor, al estar lejana a su Patria y a sus seres queridos. Es en este nivel analítico en donde radicó nuestra propuesta de estudio, considerando la prevalencia del panteón heroico construido por la historiografía decimonónica, en donde Javiera cuenta con un destacado e indiscutido sitial.

En cierta medida, nuestra propuesta es una arremetida a este discurso tradicional, al tomar por referente el cuerpo y las emociones, partiendo de la base de ser objetos culturales, mediados o condicionados por los múltiples acontecimientos acaecidos en aquel 
momento. Así emergió un cuerpo sufriente en la lejanía, alejado de la mujer aguerrida, aquella que ve su destino condicionado por ser de la familia Carrera. Mujer que apela a ser leída y que expresa su intimidad a través de sus cartas. Entre las referencias a lo político, irrumpieron sus emociones y sentimientos. Por ello que quizás este escrito resulta ser una herejía para el debate historiográfico, al recurrir a herramientas o enfoques desde las ciencias sociales, en esta interdisciplinariedad que aún está en gestación.

Independiente de su valoración, esta lectura es fascinante, ya que el epistolario nos permitió visualizar a esta mujer, cómo concibió su rol, su sentir, sus deseos mediatos y anhelos a futuro. Arremetida que aspira a ser un aporte y nueva lectura para el imaginario en torno a la madre de la Patria. Asimismo, nuestra propuesta de análisis es una cantera de estudio para la humanización de los personajes históricos, además de la resignificación de otros actores sociales, olvidados, silenciados o no valorados por la historiografía, quienes sin duda nos aportan una valiosa mirada sobre el contexto en donde vivieron, sus ideas, temores y deseos, tal como nos dio cuenta Javiera a través de sus cartas.

\section{Notas}

1 Ver Vicente Grez, 1878, 19-21.

2 Entenderemos el concepto de imaginario a partir de la propuesta de Gilbert Durand al señalar que es "el conjunto de imágenes y las relaciones de imágenes que constituye el capital pensante del homo sapiens", imaginario que se expresa o hace visible a través de discursos y representaciones $(2004,21)$.

3 Entre los autores que plantean un rol pasivo, enfatizando principalmente su condición de mujer destacada en la elite del periodo se cuenta principalmente a Benjamín Vicuña Mackenna, Vicente Grez,Diego Barros Arana, entre otros, principales constructores de la historiografía liberal del siglo XIX. La segunda interpretación sobre el rol activo de las mujeres en la Independencia, así como el caso particular de Javiera, ha sido trabajado por Patricia Peña, 1997; 2004 y Carla Ulloa, 2010.

4 Cabe señalar que los orígenes del estudio del cuerpo en la disciplina histórica se lograron a raíz del enfoque de historia de las mentalidades, principalmente en lo trabajado en Francia por la Escuela de los Annales, en donde uno de los principales temas a estudiar es el individuo y el cómo se ve condicionado o mediado por su contexto en una larga duración. Asimismo, este enfoque tiene por una de sus máximas historizar a través de otro tipo de fuentes documentales, 
alejadas de la Historia tradicional, así como el estudio de otro tipo de temáticas más allá de la oficialidad y los grandes héroes de la Nación. Para este debate ver las obras de Peter Burke, Formas de hacer historia, entre otras.

5 Este enfoque aún carece de una mayor consideración en el ámbito historiográfico nacional, a pesar de que a nivel internacional su relevancia es más destacada en el enfoque de Historia de las Mentalidades, tal como mencionamos anteriormente, en donde a través de los aportes de la sociología y la antropología, disciplinas de base para este tipo de estudios, se comenzó a concebir la relevancia del cuerpo en cuanto construcción cultural y reflejo de las transformaciones de la sociedad a través del tiempo. En esta senda teórica y metodológica, sin duda que la obra pionera de sistematización es la publicación colectiva de Michel Feher y Nadia Tazi, Fragmentos para una historia del cuerpo humano (1999) y la obra dirigida por Georges Vigarello y Alain Corbin, Historia del cuerpo (2005). Ambas obras reúnen un sinnúmero de estudios sobre distintos temas y formas de aproximarse al cuerpo. Si bien este enfoque aún no es totalmente valorado en la historiografía chilena, o está en vías de serlo, un aporte relevante a esta tarea es la publicación dirigida por Álvaro Góngora y Rafael Sagredo, Fragmentos para una historia del cuerpo en Chile (2009) que reúne los últimos trabajos chilenos realizados desde una perspectiva del cuerpo.

6 Para el caso de nuestro país, la advocación generadora de identidad y legitimadora del proceso de formación del Estado Nación es la Virgen del Carmen. Sobre este tema ver Carmen Gloria Soto, "A Ella sean dadas las glorias del Ejército". El culto ala Virgen del Carmen en la construcción del Estado-Nación en Chile: de la devoción mariana a la legitimación del poder, 1750-1850, (2009).

$7 \quad$ En la línea de reivindicación por el papel de la mujer en los procesos históricos, un punto de referencia es la obra dirigida por Michelle Perrot y Georges Duby, La historia de las mujeres en Occidente. Perspectiva seguida en el ámbito historiográfico nacional con la obra dirigida por Ana María Stuven y Joaquín Fermandois, Historia de las mujeres en Chile (que hasta el momento se ha publicado el tomo I).

8 Para una revisión más acabada de estas mujeres y su individualización en sus respectivos contextos, ver los trabajos de Patricia Peña $(1997 ; 2004)$.

9 Sobre las características de la carta privada y su valoración como fuente documental para la reconstrucción histórica, ver el artículo de Darcie Doll Castillo (2004).

10 En la historiografía nacional quien ha trabajado esta temática en el último tiempo, la concepción del cuerpo como soporte de estudio, es Alejandra Araya principalmente en el contexto colonial.

11 Con respecto a las cartas de Javiera, el principal referente con el que contamos es la publicación de Sergio Vergara, Cartas de mujeres en Chile, 1630-1885, en donde se presenta una recopilación de cartas pertenecientes a "destacadas mujeres" de la historia de nuestro país, entre las cuales se destaca Javiera. Asimismo, estas cartas fueron publicadas anteriormente en la Revista Chilena de Historia y Geografía, que en distintos números fueron publicados los "papeles de Javiera Carrera", así como también los papeles de los Carrera en donde se cuenta con las cartas de su padre, José Ignacio de la Carrera, de su cuñada Ana María Cotapos, entre otros. Por tanto, considerando estas publicaciones el 
número de cartas es más amplio, lo que aumenta con la documentación existente en el Archivo Nacional, que aún no ha sido publicada. Es a partir de esta fragmentación que hemos "armado" un epistolario, permitiéndonos ampliar la lectura a las cartas de Javiera, y establecer el lazo comunicativo, con quien mantiene correspondencia, ya sea con su esposo, su padre, o sus hermanos.

12 Javiera Carrera (J.C. en adelante) a su esposo Pedro Díaz de Valdés, en Los Andes, $1^{\circ}$ de mayo de 1810 (Vergara, 1987, 64).

13 J. C. a su esposo Pedro Díaz de Valdés, (P.D.V. en adelante) en Mendoza. Santiago, 31 de mayo de 1810 (Vergara, 1987, 71).

14 J. C. a su esposo P. D. V., en Los Andes. Santiago, 18 de mayo de 1810 (Vergara, 1987, 68).

15 J. C. a su esposo P. D. V., en Los Andes. Santiago, 20 de mayo de 1810 (Vergara, 1987, 69-70).

16 J. C a su esposo P. D. V., en Buenos Aires. Santiago, 25 de junio de 1810 (Vergara, 1987, 74).

17 J. C a su esposo P. D. V., en Buenos Aires. Santiago, 2 de julio de 1810 (Vergara, 1987, 77).

18 J. C a su esposo P. D. V., en España. Santiago, 16 de junio de 1813 (Vergara, 1987, 84-85).

19 Carta de doña Javiera de Carrera a don Pedro Díaz de Valdés, en Casa de Villarroel, 5 de octubre de 1814. En Revista Chilena de Historia y Geografía, año III, tomo VII, número 11, 1913, 197.

20 J. C a su esposo P. D. V., en Santiago. Mendoza, 15 de noviembre de 1814. (Vergara, 1987, 86).

21 Vergara, 1987, 87.

22 Vergara, 1987, 87.

23 Carta de don Pedro Díaz de Valdés a doña Javiera de Carrera, 16 de diciembre de 1814. En Revista Chilena de Historia y Geografía, año III, tomo VII, número 11, 1913, 202.

24 Carta de don Pedro Díaz de Valdés a doña Javiera de Carrera, 12 de diciembre de 1816. En Revista Chilena de Historia y Geografía, año III, tomo VII, número 11, 1913, 204.

25 Carta de don Pedro Díaz de Valdés a doña Javiera de Carrera, 16 de diciembre de 1814. En Revista Chilena de Historia y Geografía, año III, tomo VII, número 11, 1913, 205.

26 Carta de don Pedro Díaz de Valdés a doña Javiera de Carrera, 16 de diciembre de 1814. En Revista Chilena de Historia y Geografía, año III, tomo VII, número 11, 1913, 210- 212.

27 Carta de don Pedro Díaz de Valdés a doña Javiera de Carrera, 16 de diciembre de 1814. En Revista Chilena de Historia y Geografía, año III, tomo VII, número 11, 1913, 218.

28 J. C a su esposo P. D. V., en Santiago. Buenos Aires, 9 de junio de 1817 (Vergara, 1987, 89).

29 De doña Javiera de Carrera a don Pedro Díaz de Valdés. Buenos Aires, 16 de julio de 1817. En Revista Chilena de Historia y Geografía, año III, tomo VIII, número $12,1913,433$. 
30 J. C a su esposo P. D. V., en Chile. Montevideo, 8 de febrero de 1822 (Vergara, 1987, 126).

31 J. C a su hijo Pío de Valdés, en Mendoza. Santiago, 12 de abril de 1828 (Vergara, 1987, 176).

32 Como mencionamos en la introducción, este trabajo en parte es una propuesta de estudio en cuanto al cuerpo y las emociones, su vialidad y potencial en la investigación historiográfica, por ello es que muchos elementos que visualizamos en las cartas de Javiera dan pie a futuras indagaciones y un análisis más profundo, considerando también una sistematización teórica y su vinculación para la reconstrucción histórica.

\section{Bibliografía}

Arambel, María Cristina. Las mujeres toman la palabra. Escritura femenina del siglo XIX en Hispanoamérica. Madrid: editorial Iberoamericana, 2001.

Araya, Alejandra. "Cuerpo, sociedad colonial e individuo moderno en Chile: Sor Josefa de los Dolores Peña y Lillo (1739-1822). Tesis para optar al grado de doctor en Historia. México: El Colegio de México, 2007.

Barthes, Roland. Fragmentos de un discurso amoroso. México: Siglo XXI editores, 1982.

Bartra, Roger. Cultura y melancolía. Las enfermedades del alma en la España del siglo de oro. Barcelona: editorial Anagrama, 2001.

Boito, María Eugenia y José Luis Grosso (comps.) Cuerpos y Emociones desde América Latina. Córdoba: CEA-CONICET, Doctorado en Ciencias Humanas, Facultad de Humanidades, Universidad Nacional de Catamarca, 2010.

Burke, Peter. Formas de hacer historia. Madrid: Alianza. 1993.

Chambers. Sarah. "Cartas y salones: mujeres que leen y escriben la nación en la Sudamérica del siglo XIX". En Revista Araucaria. Sevilla: Universidad de Sevilla, primer semestre, vol 6, 013, 2005.

Colmenares, Germán. Convenciones contra la cultura. Ensayos sobre la historiografía hispanoamericana del siglo XIX. Santiago: Centro de Investigaciones Diego Barros Arana, 2006 (reedición).

Doll Castillo, Darcie. "La carta privada como práctica discursiva. Algunos rasgos característicos". En Revista Signos v.35, 51-52, 2002.

Elías, Norbert. El proceso civilizatorio: investigaciones sociogenéticas y psicogenéticas. México: Fondo de Cultura Económica, 1997.

Figari, Carlos y Adrián Scribano. Cuerpos, subjetividades y conflictos: hacia una sociología. Buenos Aires: Fundación Centro de Integración, Comunicación, Cultura y Sociedad - CICCUS, 2009.

Foisil, Madeleine. "La escritura del ámbito privado". En Peter Brown, Evelyne Patlagean, Paul Veyne (coord.). Historia de la vida privada. Vol. 3, Del Renacimiento a la Ilustración. Madrid: Taurus ediciones, 1989, 331-370.

Foucault, Michel. El orden del discurso. Barcelona: Tusquest editores, 1973.

Franco, Jean. Las conspiradoras. La representación de la mujer en México. México: El Colegio de México, Fondo de Cultura Económica, 1994. 
Godineau, Dominique. "Hijas de la libertad y ciudadanas revolucionarias". En George Duby y Michelle Perrot (ed.). Historia de las Mujeres en Occidente. Volumen IV, "El siglo XIX". Madrid: Taurus, 2000.

Grez, Vicente. Las Mujeres de la Independencia. Escrito en 1878 y editado por Raúl Silva Castro con un prólogo biográfico en Zigzag, Santiago, 1966.

Harwich V, Nikita. "La historia patria". En Antonio Annino y Francois Xavier Guerra (coord.). Inventando la nación. Iberoamérica siglo XIX. México: Fondo de Cultura Económica, 2003.

Le Breton, David. Antropología del cuerpo y modernidad. Buenos Aires: ediciones Nueva Visión, 1995.

------. Las pasiones ordinarias. Antropología de las emociones, Buenos. Aires: ediciones Nueva Visión. 1999.

Le Goff, Jacques y Nicolás Truong. Una historia del cuerpo en la Edad Media. España: Paidós Ibérica, 2005.

Luna Zamora, Rogelio. "La sociología de las emociones como campo disciplinario. Interacciones y estructuras sociales". En Sensibilidades en juego: Miradas múltiples desde los estudios sociales de los cuerpos y emociones. Córdoba: CEA CONICET, 2010.

Lutz, Tom. El llanto. Historia cultural de las lágrimas. Madrid: editorial Taurus, 1999.

Mauss, Marcel. "Técnicas y movimientos corporales". En Marcel Mauss. Antropología y Sociología. Madrid: editorial Tecnos, 1979.

Moulian, Luis. La Independencia de Chile: balance historiográfico. Tesis para optar al grado de licenciado en Historia, Universidad de Chile, 1994.

Muñoz, Juan Guillermo: "Mujeres y vida colonial en el Chile colonial". En Rafael Sagredo y Cristián Gazmuri (dir.) Historia de la vida privada en Chile. Tomo I. El Chile tradicional. De la Conquista a 1840. Santiago: editorial Taurus-Aguilar Chilena de Ediciones, 2005.

Peña, Patricia. Las célebres y las otras. Modelo, presencia y protagonismo femeninos en el proceso independentista chileno. Tesis para optar al grado de Magíster en Historia, mención en Historia de América. Universidad de Chile, 2004.

-----.. “... Y las mujeres, ¿dónde estuvieron?: Mujeres en el proceso independista chileno". En Anuario de Postgrado Universidad de Chile, Facultad de Filosofía y Humanidades, Escuela de Postgrado, v., n 2, oct. 1997. Santiago, La Escuela, 1997- Santiago: LOM Ediciones, 235-252.

Sociedad Chilena de Historia y Geografía. Revista Chilena de Historia y Geografía, año III, tomo VII, número 11, 1913.

------. Revista Chilena de Historia y Geografía, año III, tomo VIII, número 12 ,1913.

Soto G, Carmen Gloria. "A Ella sean dadas las glorias del Ejército". El culto a la Virgen del Carmen en la construcción del Estado-Nación en Chile: de la devoción mariana a la legitimación del poder, (1750-1850). Seminario de grado para optar al grado de Licenciada en Historia. Universidad de Chile, 2009.

Soto Vergara, Guillermo. "La creación del contexto: función y estructura en el género epistolar". En Onomazéin. Revista de Lingüística y Traducción, n¹, 1996, 152-166.

Steven, Ana María y Joaquín Fermandois (eds). Historia de las mujeres en Chile, tomo I. Santiago: editorial Taurus -Aguilar Chilena de Ediciones, 2010. 
Ulloa, Carla. “Javiera Carrera Verdugo: en torno a su imaginario político y los discursos historiográficos sobre una mujer de la Independencia". En Revista CCEHS, $n^{\circ} 2$, "Bicentenarios en Latinoamérica". Junio - Octubre 2010.

Vergara, Sergio. Cartas de mujeres en Chile, 1630-1885. Santiago: editorial Andrés Bello, 1987.

Vicuña Mackenna, Benjamín. Doña Javiera de Carrera: rasgo biográfico. Leído en el círculo de amigos de las letras el 31 de agosto de 1862. Editado por Guillermo Miranda en Biblioteca de autores chilenos, volumen XXIII. Santiago, 1904

Vovelle, Michel. Ideologías y mentalidades. Barcelona: editorial Ariel, 1985. 
